Journal of Applied Fluid Mechanics, Vol. 10, Special Issue, pp. 15-22, 2017.

Selected papers from International Conference on Newer Engineering

Concepts and Technology, ICONNECT2K17, 2017

Available online at www.jafmonline.net, ISSN 1735-3572, EISSN 1735-3645.

DOI: $10.36884 / \mathrm{jafm} .10$. SI.28266

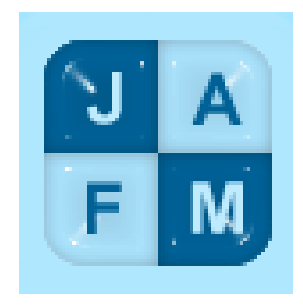

\title{
Optimization of Abrasive Water Jet Cutting Parameter for AISI 316L Stainless Steel Sheet
}

\author{
A. Parthiban ${ }^{\dagger}$, S. Sathish and M. Chandrasekaran \\ Department of Mechanical Engineering, School of Engineering, Vels University Chennai-117, India \\ †Corresponding Author Email: parthibana@yahoo.co.in
}

(Received February16, 2017; accepted July 30, 2017)

\begin{abstract}
Abrasive water jet cutting is a advanced manufacturing process to be used cut various type of material economically. The width of AWJC or kerf width is affected by Abrasive flow rate, cutting speed and stand of distance as well as the work-piece material. In this present work AWJC of stainless steel AISI 316L 2mm thickness has been investigated. Design of experiment was implemented by to applying the full factorial design method. In this work to relate the top kerf width and bottom kerf width and the above process parameters. Mathematical models were developed to evaluate the relationship between the process parameters and the top and bottom kerf width. Also, process parameters effects on the edge quality have been defined. Finally, the numerical optimization has been used to found the optimal AWJC conditions at which the highest edge quality like top and bottom kerf width can be achieved.
\end{abstract}

Keywords: Water Jet Cutting; Full factorial design; Stainless Steel; Optimization.

\section{NOMENCLATURE}

A

American Iron Steel Institute

AWJC Abrasive Water Jet Cutting

$B \quad$ cutting speed

\section{INTRODUCTION}

Water jet cutting is increasingly being used in a wide variety of applications including mining process, Medical applications etc. Abrasive water jet cutting is one of the non-traditional cutting processes capable of cutting wide range of hard-tocut materials. Abrasive Water Jet Cutting [AWJC] has distinctive in the other non-customary cutting advances, for example, no warm vitality, high machining adaptability, least weights on the work piece, cutting powers and has been exhibited to be a compelling innovation for cutting of various engineering materials. Abrasive water jet cutting process significantly affected by process parameters such as abrasive flow rate, transverse speed, stand of distance, water pressure and nozzle diameter are important for to affect the quality of cut. To evaluate the effect of jet of pressure, abrasive flow rate and work feed rate on smoothness of the surface produced by abrasive water jet machining of carbide of grade P25 Azmir (2009), They all have been studied that the impact of Abrasive Water Jet
BKW Bottom Kerf Width
C stand of distance
DF Degrees of Freedom
TKW Top Kerf Width

Machining (AWJM) process parameters on surface harshness ( $\mathrm{Ra}$ ) of glass fiber strengthened epoxy composites. It was discovered that the kind of abrasive materials, standoff distance and cutting speed were the huge control factors and the cutting introduction was the immaterial control factor in controlling the Ra. Hocheng (1994) they has completed work on the kerf development of a ceramic plate cut by a water jet cutting. There is a basic blend of water, abrasive flow rate and cross speed for all through cut beneath which it can't be accomplished for certain thickness. An adequate supply of pressure driven vitality, fine work abrasives at direct speed gives smooth kerf surface. John Rozario (2005) has been worked away at technique for effective and quality cutting of materials with abrasive flow rate considering the variety in opening and nozzle diameter in cutting 6063-T6 aluminum amalgam, For maintaining less taper on kerf. Increase in the size of orifice and focusing nozzle is not much effect the surface quality but larger sizes of orifice produce a better surface finish on cut surface and the Wang (1999). 
done investigation of grating water fly cutting of metallic covered sheet steels in light of a measurably outlined analysis. They examined connections between kerf qualities and process parameters. They produce empirical models for kerf geometry and quality for the prediction and optimization of AWJ cutting performance. Mahabalesh (2007). was Investigate the impacts of the diverse synthetic conditions like phosphoric acid and polymer (polyacrylamide) in the proportion of $30 \%$ with $70 \%$ of water and standoff distance on the decrease points and material expulsion rates of drilled holes in the grating water jet machining process. Material expulsion is most astounding when slurry added with polymer contrast with three slurries. Chithirai Pon Selvan (2007) the influence of process parameters on depth of cut which is an important cutting performance measure in abrasive water jet cutting of stainless steel. And to develop the empirical model for the prediction of depth of cut in abrasive water jet cutting of stainless steel is developed using regression analysis, FarhadKolahan (2009) the impacts of process parameters settings on Abrasive Water jet machining of AA 6063-T6 aluminum composite have been explored. Measurable relapse investigation has been utilized to create numerical models relating such process parameters as abrasive flow rate, transverse rate and diameter of nozzle to the distance through of cut.

The previous research on kerf dimension had less attention for best parameter selection on AISI 316 L stainless steel sheets during Abrasive water jet cutting. But few works were employed in the full factorial design, RSM, Artificial Neural Network and Fuzzy logic for predicting the parameters in AWJC AhmetHascalik(2007),Khan(2007) and Marek (2014). In this way the fundamental point of this work is to create numerical model utilizing full factorial plan, to enhance the AWJC operation.

\section{METHODOLOGY}

The Abrasive water jet cutting process considered in this work AISI 316L Stainless steel sheet for straight profile is discussed following section.

\subsection{Experimental Procedure}

The experiments were done by Micro step aqua cut AWJC machine as shown in Fig. 1 and the work piece considered for this work is stainless steel AISI 316 L 2mm thickness sheet. Cutting operation carried out on work piece with Straight profile Mayur (2014) as shown Fig.2. The input parameters considered are Abrasive Flow Rate, cutting speed and Stand of distance. The considered parameters ranges are the Abrasive flow rate in between (175-225 Gram/min), Cutting Speed levels are within $(250 \mathrm{~mm} / \mathrm{min}$ $350 \mathrm{~mm} / \mathrm{min})$, Stand of distance was $(2-4 \mathrm{~mm})$ and $2 \mathrm{~mm}$ Work piece thickness. The 27 experimental runs were conducted based on full factorial design approach Vishal (2015). The collected experimental data were given in Table 2.

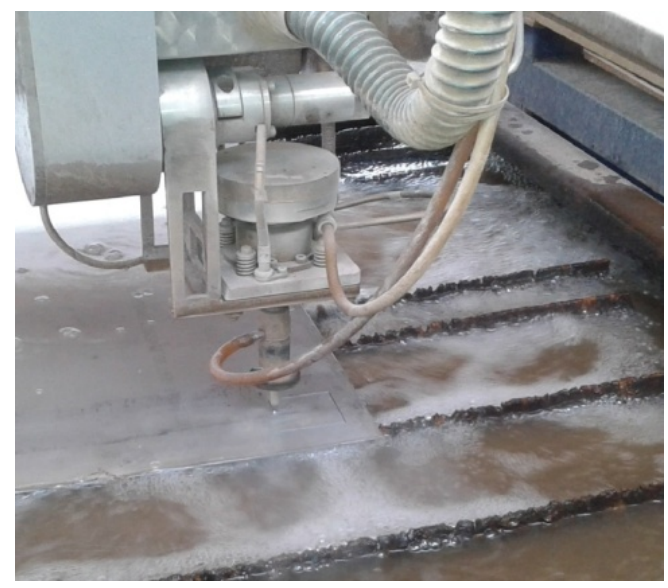

Fig. 1. AWJC Machine.

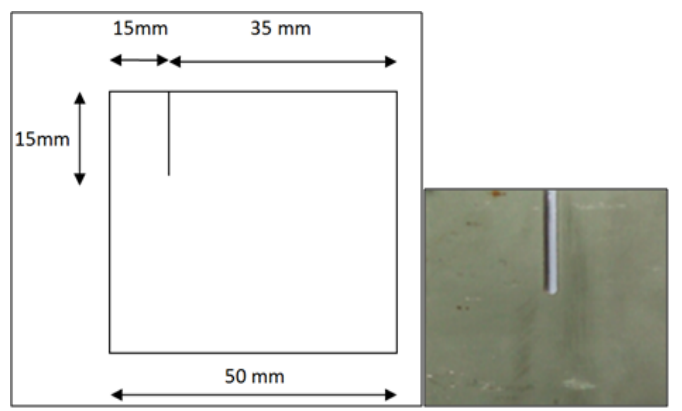

Fig. 2.Work piece image.

Table 1 process variables and design levels

\begin{tabular}{|c|c|c|c|}
\hline Name / Level & -1 & 0 & +1 \\
\hline $\begin{array}{c}\text { Abrasive Flow Rate } \\
\text { (Gram/min) }\end{array}$ & 175 & 200 & 225 \\
\hline $\begin{array}{c}\text { Cutting Speed } \\
\text { (mm/min) }\end{array}$ & 250 & 300 & 350 \\
\hline $\begin{array}{c}\text { Stand of Distance } \\
(\mathrm{mm})\end{array}$ & 2 & 3 & 4 \\
\hline
\end{tabular}

\subsection{Measurement of Response}

To quantify the top kerf width and bottom Kerf width by indirect measurement using Tool makers microscope with 10X magnification factor, the work piece hold on the work table.

The Design Expert Software, form 6.0 in light of full factorial plans was utilized to play out the factual investigation and create the regression model Eltawhni (2012). The parameters of in this work included three numerical factors of Abrasive flow rate, Cutting speed and stand of distance Table 1 shows the ranges of the independent variables and experimental design levels which were used in this work. The Table 2 shows the complete experimental design of this work. 
A. Parthiban et al. / JAFM, Vol. 10, Special Issue, pp. 15-22, 2017.

Table 2 Experimental Data

\begin{tabular}{|c|c|c|c|c|c|}
\hline SI.No & $\begin{array}{l}\text { Flow Rate } \\
\text { (Gram/ min) }\end{array}$ & $\begin{array}{l}\text { Cutting Speed } \\
(\mathrm{mm} / \mathrm{min})\end{array}$ & $\begin{array}{c}\text { Stand of Distance } \\
(\mathrm{mm})\end{array}$ & $\begin{array}{l}\text { Top Kerf width } \\
\text { (mm) }\end{array}$ & $\begin{array}{c}\text { Bottom Kerf Width } \\
(\mathrm{mm})\end{array}$ \\
\hline 1 & 175 & 250 & 3 & 0.8087 & 0.7614 \\
\hline 2 & 175 & 350 & 3 & 0.8191 & 0.7698 \\
\hline 3 & 175 & 300 & 2 & 0.7089 & 0.6768 \\
\hline 4 & 175 & 300 & 4 & 0.8979 & 0.8344 \\
\hline 5 & 175 & 250 & 2 & 0.7193 & 0.6892 \\
\hline 6 & 175 & 250 & 4 & 0.9083 & 0.8402 \\
\hline 7 & 175 & 300 & 3 & 0.7979 & 0.7558 \\
\hline 8 & 175 & 350 & 2 & 0.7191 & 0.6928 \\
\hline 9 & 175 & 350 & 4 & 0.9179 & 0.8538 \\
\hline 10 & 200 & 250 & 2 & 0.7428 & 0.7117 \\
\hline 11 & 200 & 300 & 4 & 0.9286 & 0.8625 \\
\hline 12 & 200 & 250 & 4 & 0.9384 & 0.8713 \\
\hline 13 & 200 & 350 & 4 & 0.9393 & 0.8762 \\
\hline 14 & 200 & 250 & 3 & 0.8381 & 0.7887 \\
\hline 15 & 200 & 350 & 3 & 0.8584 & 0.8063 \\
\hline 16 & 200 & 300 & 2 & 0.7576 & 0.7255 \\
\hline 17 & 200 & 350 & 2 & 0.7643 & 0.7312 \\
\hline 18 & 200 & 300 & 3 & 0.8645 & 0.8274 \\
\hline 19 & 225 & 250 & 3 & 0.8735 & 0.8274 \\
\hline 20 & 225 & 350 & 3 & 0.8853 & 0.8366 \\
\hline 21 & 225 & 300 & 2 & 0.7878 & 0.7547 \\
\hline 22 & 225 & 300 & 4 & 0.9487 & 0.8866 \\
\hline 23 & 225 & 250 & 2 & 0.7721 & 0.7385 \\
\hline 24 & 225 & 250 & 4 & 0.9565 & 0.8914 \\
\hline 25 & 225 & 300 & 3 & 0.8857 & 0.8386 \\
\hline 26 & 225 & 350 & 2 & 0.7992 & 0.7641 \\
\hline 27 & 225 & 350 & 4 & 0.9681 & 0.9061 \\
\hline
\end{tabular}

Table 3 ANOVA table for top kerf width

\begin{tabular}{|c|c|c|c|c|c|}
\hline \multirow{2}{*}{ Source } & Sum of squares & DF & Mean square & $\begin{array}{c}\mathrm{F} \\
\text { Value }\end{array}$ & $\mathrm{p}$-value \\
\hline Model & 0.1683 & 9 & 0.0187 & 287.29 & $<0.001$ \\
\hline $\mathrm{A}$ & 0.0187 & 1 & 0.0187 & 286.89 & $<0.001$ \\
\hline $\mathrm{B}$ & 0.0007 & 1 & 0.0007 & 10.897 & 0.0042 \\
\hline $\mathrm{C}$ & 0.1481 & 1 & 0.1481 & 2274.1 & $<0.001$ \\
\hline $\mathrm{AB}$ & 0.0001 & 1 & 0.0001 & 1.2065 & 0.2873 \\
\hline $\mathrm{AC}$ & 0.0003 & 1 & 0.0003 & 5.0166 & 0.0388 \\
\hline $\mathrm{BC}$ & 0.0001 & 1 & 0.0001 & 0.8855 & 0.3599 \\
\hline $\mathrm{A} \wedge 2$ & 0.0001 & 1 & 0.0001 & 2.3043 & 0.1474 \\
\hline $\mathrm{B} \wedge 2$ & 0.0001 & 1 & 0.0001 & 1.5243 & 0.2338 \\
\hline $\mathrm{C} \wedge 2$ & 0.0001 & 1 & 0.0001 & 2.1830 & 0.1578 \\
\hline $\mathrm{R} 2 \mathrm{n}$ & 0.0011 & 17 & 0.0001 & & \\
\hline total & 0.1694 & 26 & & & \\
\hline
\end{tabular}




\section{RESULT AND DISCUSSION}

\subsection{Analysis Of Variance (ANOVA)}

ANOVA is the statistical method used to calculate the size of the difference between data set.

The main elements of ANOVA table are source of variance, sum of squares, degrees of freedom, mean square, $\mathrm{F}$ ratio, and the probability associated with the F ratio Gopalakannan (2013), Forghany (2017) and Mollaabbasi (2016).

The source of variance deals with independent variables that are called factors such as Abrasive flow rate, Cutting speed and stand of distance

From the ANOVA table The Model F-estimation of 287.30 suggests the model is critical. There is just a $0.01 \%$ shot that a "Model F-Value" this huge could happen because of commotion. Estimations of "Prob> F" under 0.0500 show display terms are noteworthy. For this situation A, B, C, AC are critical model terms The Model F-estimation of 151.35 infers the model is critical. There is just a $0.01 \%$ shot that a "Model F-Value" this vast could happen because of noise. Values of "Prob> F" under 0.0500 show display terms are huge. For this situation A, B, C is huge model terms.

\subsection{Response Surface Models}

RS model, which is an analytical function in predicting Top kerf width and Bottom kerf width values. The generalized form of response surface models is shown in Eq. 1 Adeeb (2016).

$$
R a=b_{0}+\sum_{i=1}^{3} b_{i} X_{i}+\sum_{i=1}^{3} b_{i i} X_{i i}^{2}+\sum_{i=1}^{3} \sum_{j=1}^{3} b_{i j} X_{i} X_{j}+\varepsilon
$$

Where $\mathrm{X} 1, \mathrm{X} 2$, and $\mathrm{X} 3$ be a symbol of Abrasive flow rate, Cutting speed and stand of distance correspondingly $\mathrm{Xi} 2$ and $\mathrm{XiXj}$, the squares and interaction terms of these input factors; the constants b, the regression coefficients of parameters and $\varepsilon$, the experimental error. The quadratic mathematical models have been developed to predict the Top kerf width and bottom kerf width. The developed mathematical models for AISI 316L sheet as shown in equations.

$$
\begin{aligned}
& T K W=+0.0218+4.5 e^{-3} \times A-1.12 e^{-3} \times B \\
& +0.174 \times C+2.04 e^{-6} \times A \times B-2.08 e^{-4} \times A \\
& \times C-4.38 e^{-5} \times B \times C-8 e^{-6} \times A^{2}+1.626 e^{-6} \\
& \times B^{2}-4.86 e^{-3} \times C^{2} . \\
& B K W=-0.0161+4.18 e^{-3} \times A-5.39 e^{-4} \\
& \times B+0.149 \times C+1.59 e^{-6} \times A \times B-1.42 e^{-4} \\
& \times A \times C-1.42 e^{-4} \times A \times C-2.58 e^{-5} \times B \times \\
& C-7.41 e^{-6} \times A^{2}+7.13 e^{-7} \times B^{2}-6.5 e^{-3} \times C^{2} .
\end{aligned}
$$

The Fig. 3 represents the effect of Abrasive flow rate and cutting speed on AISI 316L stainless steel
$2 \mathrm{~mm}$ thickness sheet as work piece materials. Initially the machining top kerf width is very low (range from 0.78 to $0.80 \mathrm{~mm}$ ) at the abrasive flow rate is $180-190 \mathrm{gm} / \mathrm{min}$ while the cutting speed is range from $260-340 \mathrm{~mm} / \mathrm{min}$. During the cutting best kerf width is steadily expanded as for increment the abrasive flow rate and cutting speed. The best kerf width is most extreme (0.86-0.88 mm) at the abnormal state of abrasive flow rate (210-220 $\mathrm{gm} / \mathrm{min}$ ) while all level of cutting speed.

The Fig. 4 shows, at constant abrasive flow rate of $220 \mathrm{gm} / \mathrm{min}$ for increasing cutting speed top kerf width increases. At constant stand of distance of 2 $\mathrm{mm}$ for increasing abrasive flow rate the top kerf width increases. At maximum abrasive flow rate and minimum stand of distance the top kerf width also minimum.Based on ANOVA discussion, one means of doing this is to represent cutting outcomes mathematically as a function of the applicable cutting parameters. The Figs. 5-6 presents the response surface of the bottom kerf width according to the change of the cutting parameter for AISI 316L 2mm thickness of material.

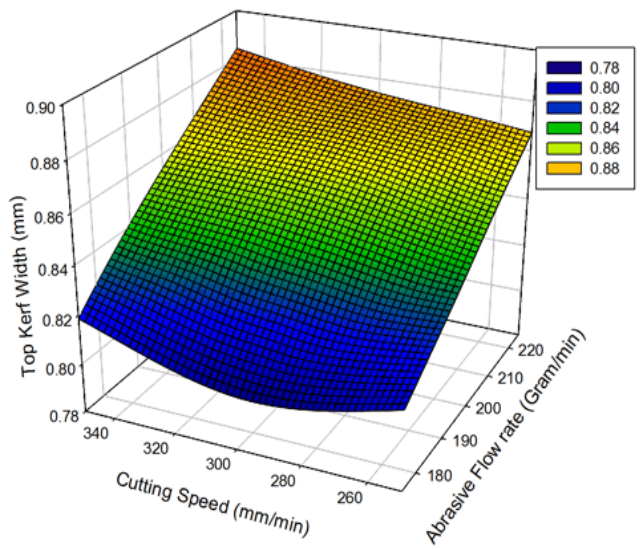

Fig. 3. Effect of abrasive flow rate and cutting speed on top kerf width.

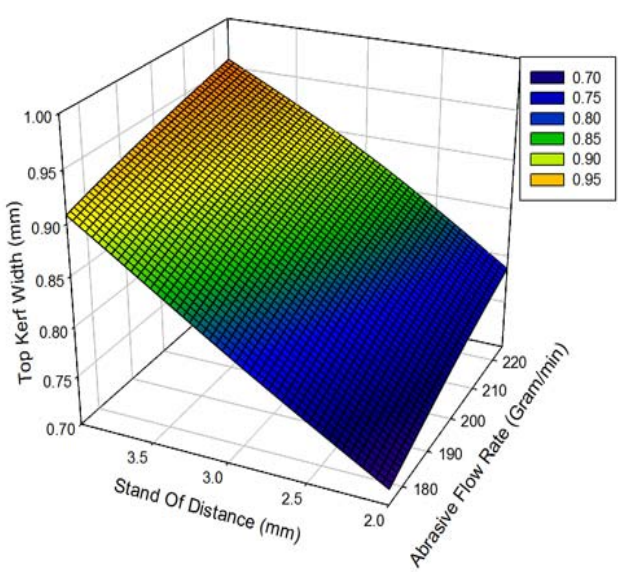

Fig. 4. Effect of abrasive flow rate and stand of distance on top kerf width.

After thorough thoughtful of the problem and the analysis performed, similar effect has been 
observed between the bottom kerf width. Also the interaction effect between the independent and dependent variables for both are the same. However, the analyzed and measured values of top kerf width and bottom kerf width for straight cut profile are observed to be minimum when compared with top kerf width for $2 \mathrm{~mm}$ thickness of AISI 316 $\mathrm{L}$ sheet. This is due to the fact that abrasive flow rate exerts to reduce the kinetic energy on the part. So that to reduce the bottom kerf width.

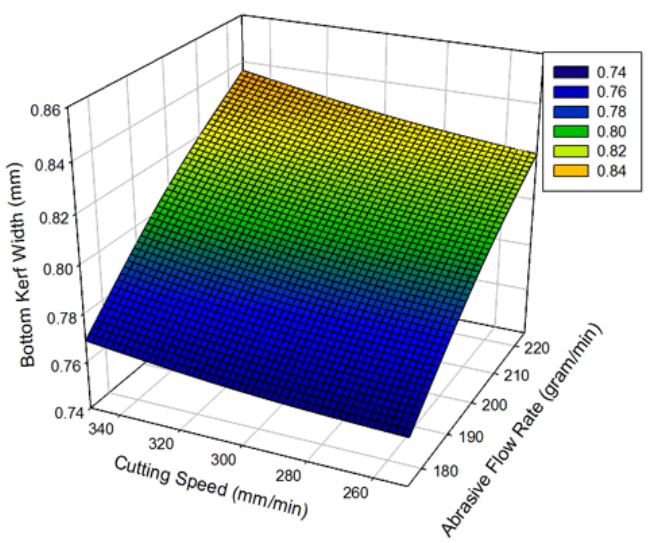

Fig . 5. Effect of abrasive flow rate and cutting speed on Bottom kerf width.

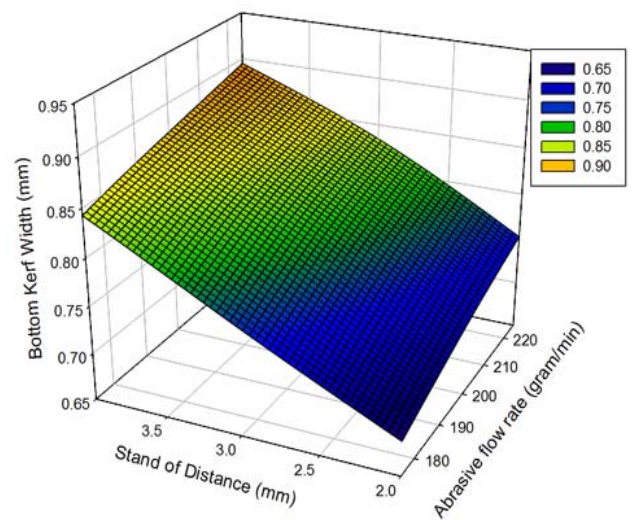

Fig. 6. Effect of abrasive flow rate and stand of distance on Bottom kerf width.

\section{VALIDATIONOF EXPERIMENTAL RESULTS}

In order to predict and verify the improvement in the top kerf width and bottom kerf width for cutting of AISI316L stainless steel sheet for $2 \mathrm{~mm}$ thickness on straight profile with respect to the chosen initial parameter setting, confirmation tests are used.

Figures 7 and 8 Demonstrates the approval of trial comes about for the top kerf width and bottom kerf width by Eqs. 2 And 3 and the exploratory esteem are little. In this way, the created conditions for top kerf width and bottom kerf width can be utilized to effectively foresee the top kerf width and bottom kerf width for any blend of AWJC parameters inside the scope of experimentation.

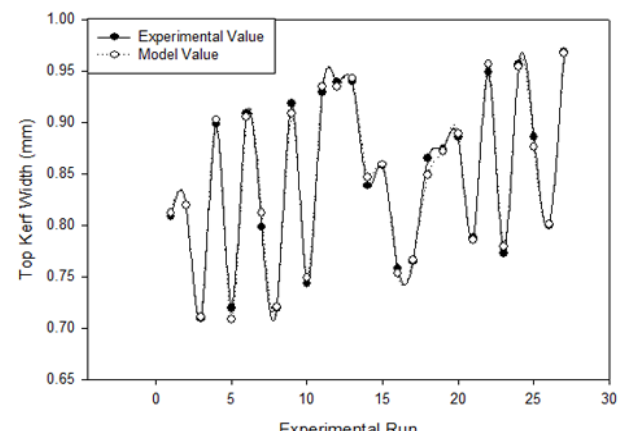

Fig. 7. Top kerf width on Experimental vs Model value.

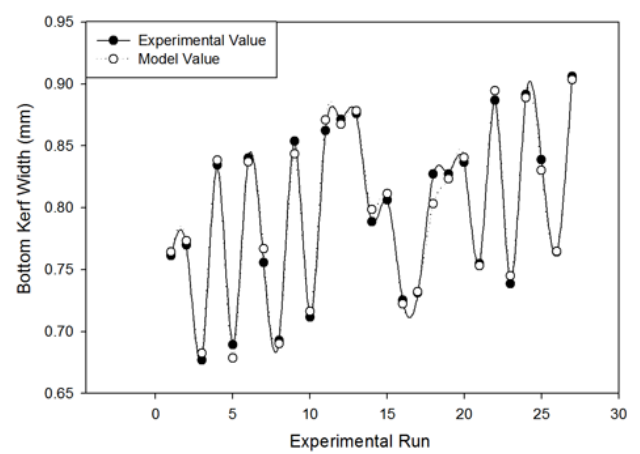

Fig. 8. Bottom kerf width on Experimental vs Model value.

\section{OPTIMIZATION}

Optimizationis the process of finding the conditions that give the maximum or minimum value of a function. Optimization, in its broadest sense, can be applied to solve any engineering problem Trancossi (2016). In view of to achieving higher production rate with high quality, in AWJC process parameters can be optimized for the quality requirement. In this work numerical optimization was used, the multi response optimization is solved desirability approach by using design expert software. The numerical optimization is set the goal as shown in Table 4 to minimize the response to achieve high quality.

Table 5 shows the optimized value for AISI 316L $2 \mathrm{~mm}$ thickness sheet of input parameters to the corresponding response value. the finally to predicted the response value top kerf width 0.7087 $\mathrm{mm}$ and bottom kerf width $0.6845 \mathrm{~mm}$ has been achieved.

The Fig. 9 indicates overlay plot drawn between the Abrasive flow rate and cutting speed the remain of stand of distance at $2 \mathrm{~mm}$. These scopes of graphical advancement result appears on the Fig. 9.the shaded territory on the overlay plot districts are to be accomplished for proposed criteria and select the ideal cutting states of AWJC. 
A. Parthiban et al. / JAFM, Vol. 10, Special Issue, pp. 15-22, 2017.

Table 4 ANOVA table for Bottom kerf width

\begin{tabular}{|c|c|c|c|c|c|}
\hline Source & Sum of saurares & $\mathrm{DF}$ & Mean square & F Value & p-value Prob $>F$ \\
\hline Model & 0.1189 & 9 & 0.0132 & 151.3 & $<0.0001$ \\
\hline A & 0.0180 & 1 & 0.0180 & 206.6 & $<0.0001$ \\
\hline B & 0.0008 & 1 & 0.0008 & 8.72 & 0.0089 \\
\hline $\mathrm{C}$ & 0.0995 & 1 & 0.0995 & 1139 & $<0.0001$ \\
\hline $\mathrm{AB}$ & 0.0001 & 1 & $4 \mathrm{E}-05$ & 0.545 & 0.4703 \\
\hline AC & 0.0002 & 1 & 0.0002 & 1.749 & 0.2035 \\
\hline $\mathrm{BC}$ & $2 \mathrm{E}-05$ & 1 & 2E-05 & 0.229 & 0.6381 \\
\hline $\mathrm{A}^{\wedge} 2$ & 0.0001 & 1 & 0.0001 & 1.475 & 0.2410 \\
\hline $\mathrm{B} \wedge^{\wedge}$ & 2E-05 & 1 & $1 \mathrm{E}-05$ & 0.218 & 0.6460 \\
\hline$C^{\wedge} 2$ & 0.0003 & 1 & 0.0003 & 2.904 & 0.1065 \\
\hline Res & 0.0015 & 17 & 8E-05 & & \\
\hline Total & 0.1204 & 26 & & & \\
\hline
\end{tabular}

Table 5 Criteria for Numericaloptimization

\begin{tabular}{|c|c|c|c|c|}
\hline Name & Goal & Lower Limit & Upper Limit & Importance \\
\hline $\begin{array}{c}\text { Abrasive flow rate } \\
\text { (Gram/min) }\end{array}$ & is in range & 175 & 225 & 3 \\
\hline Cutting speed (mm/min) & is in range & 250 & 350 & 3 \\
\hline Stand of distance (mm) & is in range & 2 & 4 & 3 \\
\hline Top Kerf Width (mm) & minimize & 0.7089 & 0.9681 & 5 \\
\hline Bottom Kerf Width (mm) & minimize & 0.6768 & 0.9061 & 5 \\
\hline
\end{tabular}

Table 6 Optimization result for cutting conditions

\begin{tabular}{|c|c|c|c|c|c|}
\hline $\begin{array}{c}\text { SI. } \\
\text { NO }\end{array}$ & $\begin{array}{c}\text { Abrasive flow rate } \\
(\text { Gram/min })\end{array}$ & $\begin{array}{c}\text { Cutting speed } \\
(\mathrm{mm} / \mathrm{min})\end{array}$ & $\begin{array}{c}\text { Stand of distance } \\
(\mathrm{mm})\end{array}$ & $\begin{array}{c}\text { Top Kerf Width } \\
(\mathrm{mm})\end{array}$ & $\begin{array}{c}\text { Bottom Kerf } \\
\text { Width (mm) }\end{array}$ \\
\hline 1 & 175 & 250 & 2 & 0.7087 & 0.6845 \\
\hline 2 & 175 & 253 & 2 & 0.7086 & 0.6849 \\
\hline 3 & 175 & 255 & 2 & 0.7085 & 0.6852 \\
\hline 4 & 175 & 256 & 2 & 0.7085 & 0.6853 \\
\hline 5 & 175 & 266 & 2 & 0.7084 & 0.6865 \\
\hline 6 & 175 & 268 & 2 & 0.7084 & 0.6869 \\
\hline 7 & 175 & 276 & 2 & 0.7086 & 0.6879 \\
\hline 8 & 176 & 250 & 2 & 0.7120 & 0.6868 \\
\hline 9 & 175 & 288 & 2 & 0.7094 & 0.6895 \\
\hline 10 & 175 & 290 & 2 & 0.7095 & 0.6897 \\
\hline
\end{tabular}

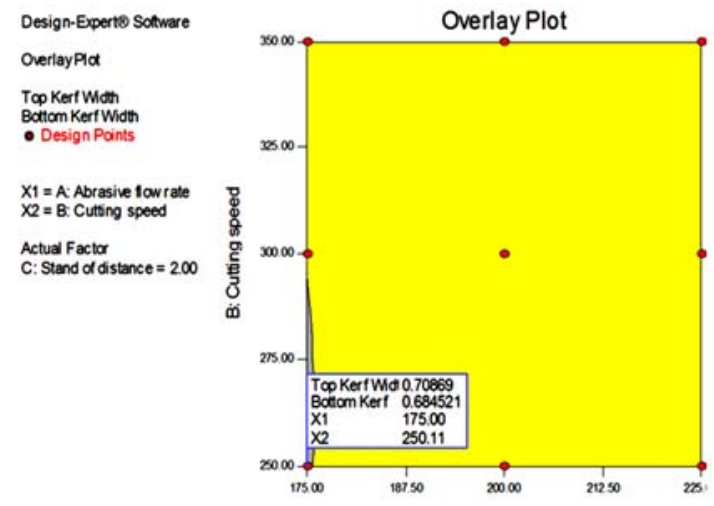

Fig. 9. Over lay plot shows the region of optimal cutting condition. 


\section{CONCLUSION}

This work to discoveries the test Examination of the impact of abrasive flow rate, cutting speed rate and stand of distance on the top kerf width and bottom kerf width in AWJC for AISI 316L 2mm thickness stainless steel sheet the accompanying conclusions are made

- The ANOVA tables of the top kerf width and bottom kerf width demonstrates the models are important the probability is $<0.0001$.

- The numerical optimisation is completed the blends of process parameters are distinguished to accomplish the minimum top and bottom kerf widths.

- $\quad$ The abrasive flow rate assumes a prevailing part in the cutting states of AISI 316L 2mm thickness sheet. This shows that the high cutting rate and least stand of distance to accomplish little top and bottom kerf widths.

- Response graph can be utilized graphically to select the cutting parameters and giving the favored top and bottom kerf width are esteems.

- The top and bottom kerf widths are gotten from the investigation were $0.7087 \mathrm{~mm}$ and $0.6845 \mathrm{~mm}$, when the procedure parameters, for example, cutting speed rate, abrasive flow rate and depth of cut were kept up at 175 gram $/ \mathrm{min}, 250 \mathrm{~mm} / \mathrm{min}$, and $2 \mathrm{~mm}$. It is conceivable to acquire the top and bottom kerf widths utilizing the above estimations of process parameters.

\section{ACKNOWLEDGEMENTS}

The authors wish to thank Biramha machine tools Tiruchirappalli for the technical support of this work.

\section{REFERENCES}

Adeeb, E., A. Maqsood, A. Musthaq and C. H. Sohn (2016). Parametric Study and Optimization of Ceiling Fan Blades for Improved Aerodynamic Performance. Journal of Applied Fluid Mechanics 9(6), 2905-2916.

Ahmet, H., C. Ulas and H. Guru (2007). Effect of traverse speed on abrasive water jet machining of Ti-6Al-4V alloy. Materials and Design 28, 1953-1957.

Azmir ,M. A. and A. K. Ahsan (2009). A study of abrasive water jet machining process on glass/epoxy composite laminate. Journal of Materials Processing Technology 209, 61686173.

Chithirai Pon Selvan, M. and N. Mohana Sundara Raju (2007). Assessment of process parameters in abrasive water jet cutting of stainless steel.International Journal of
Advances in Engineering \& Technology 1(3), 34-40.

Eltawhni, H. A., M. Hagino, K. Y. Benyounis, T. Inove and A. G. Olabi (2012). Effect of CO2 laser cutting parameters on edge quality and operating cost of AISI 316L.Optics \& laser Technology 44, 1068-1082.

Farhad Kolahan, A. and H. Khajavi (2009). Modeling and Optimization of Abrasive Water jet Parameters using Regression Analysis. World Academy of Science, Engineering and Technology 35, 488-493.

Forghany, F., M. Taeibe Rahni and A. Asadollahi Ghohieh (2017). Numerical Investigation of Optimization of Injection Angle Effects on Fluidic Thrust Vectoring. Journal of Applied Fluid Mechanics 10(1), 157-167.

Gopalakannan, S., T. Senthilvelan and S. Ranganathan (2013). Statistical optimization of EDM parameters on machining of aluminum Hybrid Metal Matrix composite by applying Taguchi based Grey analysis. Journal of Scientific \& Industrial Research 72,358-365.

Hocheng, K. R. and Chang (1994). Material removal analysis in abrasive water jet cutting of ceramic plates. Journal of Materials Processing Technology 40, 287-304.

John Rozario Jegaraj, J. and N. Ramesh Babu (2005). A strategy for efficient and quality cutting of materials with abrasive water jets considering the variation in orifice and focusing nozzle diameter. International Journal of Machine Tools \& Manufacture 45, 1443-1450.

Khan, A. A. and M. M. Hague (2007). Performance of different abrasive material during abrasive water jet machining of glass. Journal of Materials Processing Technology 191, 404407.

Mahabalesh, P. (2007). A study of taper angles and material removal rates of drilled holes in the abrasive water jet machining process. Journal of Materials Processing Technology 18, 292295.

Marek, S. W. (2014). Tomasz Pfeifer influence of cutting technology on properties of the cut edges. Advances in manufacturing science and technology 38(2), 63-72.

Mayur, C. P., B. P. Sandep and H. P. Rakesh (2014). A review on parametric study and development in abrasive water jet machining. International Journal for Technological Research in Engineering 1(9), 845-853.

Mollaabbasi, R. and J. Mohebbi Najmabad (2016). Experimental Investigation and Optimization of Solid Suspension in Non-Newtonian Liquids at High Solid Concentration. Journal of Applied Fluid Mechanics 9(4), 1907-1914.

Trancossi, M., J. Stewart, M. Subhash and D. Angeli (2016) Mathematical Model of a 
A. Parthiban et al. / JAFM, Vol. 10, Special Issue, pp. 15-22, 2017.

ConstructalCoanda Effect Nozzle. Journal of Applied Fluid Mechanics 9(6), 2813-2822.

Vishal, S., R. S. Jadoun and S. Gupta (2015). A review paper on most significant and sub significant parameters of abrasive water jet machining. International journal of advance research in science and engineering 4 (01), 249-256.

Wang, J. and W. C. K. Wong (1999). A study of abrasive water jet cutting of metallic coated sheet steels. International Journal of Machine Tools \& Manufacture 39, 855-870. 